\title{
Erratum to: Magnetorheological Fluids Based on Star-Shaped and Linear Polydimethylsiloxanes
}

\author{
S. A. Kostrov ${ }^{a, b}$, P. A. Tikhonov ${ }^{c}$, A. M. Muzafarov ${ }^{a, b, c}$, and E. Yu. Kramarenko ${ }^{a, b, *}$ \\ ${ }^{a}$ Faculty of Physics, Moscow State University, Moscow, 119991 Russia \\ ${ }^{b}$ Nesmeyanov Institute of Organoelement Compounds, Russian Academy of Sciences, Moscow, 119991 Russia \\ ${ }^{c}$ Enikolopov Institute of Synthetic Polymer Materials, Russian Academy of Sciences, Moscow, 117393 Russia \\ *e-mail: kram@polly.phys.msu.ru
}

Received June 21, 2021; revised June 21, 2021; accepted June 21, 2021

DOI: $10.1134 /$ S0965545X21330014

The article "Magnetorheological Fluids Based on Star-Shaped and Linear Polydimethylsiloxanes," written by S. A. Kostrov, P. A. Tikhonov, A. M. Muzafarov, and E. Yu. Kramarenko, was originally published electronically in Springer-Link on 27 April 2021 without Open Access. After publication in volume 63, issue 3, pages 296-306 the authors decided to make the article an Open Access publication. Therefore, the copyright of the article has been changed to (C) The Author(s), 2021 and the article is forthwith distributed under the terms of a
Creative Commons Attribution 4.0 International License (http://creativecommons.org/licenses/by/4.0/, CC BY), which permits use, duplication, adaptation, distribution and reproduction of a work in any medium or format, as long as you cite the original author(s) and publication source, provide a link to the Creative Commons license, and indicate if changes were made.

The original article can be found online at https://doi.org/10.1134/S0965545X2103007X 